\title{
Breast Cancer Outcomes Following Immediate Breast Reconstruction with Implants Versus Autologous Flaps: A Propensity Score-Matched Study
}

Zhen-Yu Wu ( $\nabla$ wuzyps@gmail.com )

Shanghai East Hospital https://orcid.org/0000-0003-1731-6370

Jing Han

Shanghai East Hospital

Hee Jeong Kim

Asan Medical Center

Jong Won Lee

Asan Medical Center

II Yong Chung

Asan Medical Center

Jisun Kim

Asan Medical Center

Sae byul Lee

Asan Medical Center

Byung-Ho Son

Asan Medical Center

Hyun Ho Han

Asan Medical Center

Jin Sup Eom

Asan Medical Center

Jae Ho Jeong

Asan Medical Center

Gyungyub Gong

Asan Medical Center

Hak Hee Kim

Asan Medical Center

Sei-Hyun Ahn

Asan Medical Center

Beom Seok Ko

Asan Medical Center

https://orcid.org/0000-0001-7831-7874 


\section{Research Article}

Keywords: Breast cancer, immediate breast reconstruction, implant, autologous flap, oncologic safety Posted Date: April 14th, 2021

DOI: https://doi.org/10.21203/rs.3.rs-397221/v1

License: (c) (1) This work is licensed under a Creative Commons Attribution 4.0 International License. Read Full License

Version of Record: A version of this preprint was published at Breast Cancer Research and Treatment on November 10th, 2021. See the published version at https://doi.org/10.1007/s10549-021-06350-0. 


\section{Abstract \\ Purpose}

A large proportion of patients with breast cancer who had mastectomy had undergone breast reconstruction with implants or autologous flaps. However, only a few studies have compared the breast cancer outcomes between the implant-based reconstruction (IBR) and autologous flap reconstruction (AFR). In this study, we retrospectively compared the local recurrence rates, distant metastasis rates, and survival outcomes between immediate IBR and AFR.

\section{Methods}

A total of 1530 patients with primary breast cancer who underwent IBR or AFR with nipple-/skin-sparing mastectomy were included. Patients who underwent neoadjuvant systemic therapy were excluded from the study. After propensity score matching by age at diagnosis, T stage, $\mathrm{N}$ stage, molecular subtype, mastectomy type, adjuvant radiotherapy status, and follow-up period, 938 patients were 1:1 matched, comprising the well-balanced IBR and AFR groups. Locoregional recurrence-free survival (LRRFS), disease-free survival (DFS), distant metastasis-free survival (DMFS), and breast cancer-specific survival (BCSS) were compared between the matched groups.

\section{Results}

After matching, the median follow-up periods were 68 months and 71 months for the IBR and AFR groups, respectively. No significant differences were observed between the IBR and AFR groups regarding the local recurrence $(7.2 \%$ vs. $5.1 \% ; P=0.175)$, regional recurrence $(2.1 \%$ vs. $1.5 \% ; P=0.463)$, or distant metastasis (3.2\% vs. 3.2\%; $P=1.000)$ rates. Moreover, no significant difference was observed between the IBR and AFR groups in the LRRFS (hazard ratio, $0.691 ; 95 \% \mathrm{Cl}, 0.433-1.102 ; P=0.118$ ), DFS (hazard ratio, $0.709 ; 95 \% \mathrm{Cl}, 0.468-1.076 ; P=0.104$ ), DMFS (hazard ratio, $1.006 ; 95 \% \mathrm{Cl}, 0.491-2.059 ; P=0.987$ ), or BCSS (hazard ratio, $0.445 ; 95 \% \mathrm{Cl}, 0.111-1.786 ; P=0.659$ ).

\section{Conclusion}

In this propensity score-matched analysis of oncologic outcomes in patients with primary breast cancer who underwent immediate breast reconstruction with nipple-/skin-sparing mastectomy, no significant differences were observed between the IBR and AFR groups.

\section{Introduction}

With the tremendous improvement in breast cancer survivorship [1, 2], the quality of life (QoL) of patients has become an important aspect that requires consideration in the treatment strategy for breast cancer 
[3]. Breast reconstruction provides substantial body image and QoL benefits in patients receiving mastectomy [4, 5]. In the recent decade, immediate breast reconstruction in conjunction with nipplesparing mastectomy (NSM) or skin-sparing mastectomy (SSM) has gained popularity $[6,7]$. Meanwhile, postmastectomy reconstruction options mainly include implant-based reconstruction (IBR) and autologous flap reconstruction (AFR) in the current clinical practice. Previous studies have demonstrated that breast reconstruction using either implants or autologous tissue does not increase the risk of breast cancer recurrence compared to conventional mastectomy without reconstruction [8-12]. However, few studies have compared breast cancer outcomes between the IBR and AFR [13]. Conversely, an increasing number of recent reports on breast implant-associated anaplastic large cell lymphoma (BIA-ALCL) have raised concerns about the unexpected impact of implants on carcinogenicity [14-17]. Moreover, patients with breast cancer who had undergone or plan to undergo IBR should know about the relationship between breast implants and cancer recurrence or the differences in recurrence risk between IBR and AFR. A detailed evaluation of the oncologic significance of the different breast reconstruction methods can greatly help in the shared decision-making process between physicians and patients.

Therefore, this matched comparative study aimed to evaluate the difference in the local recurrence rates, distant metastasis rates, or survival outcomes between NSM/SSM with IBR and AFR.

\section{Methods}

\section{Study Population}

After obtaining the institutional review board's approval, all patients who underwent NSM/SSM and immediate breast reconstruction for breast cancer between January 2010 and December 2016 at the Asan Medical Centre, Seoul, Korea, were reviewed from a prospectively maintained database. Patients who underwent neoadjuvant systemic therapy and are presenting with inflammatory breast cancer or T4 disease, synchronous distant metastasis, or recurrent disease were excluded from the study. A total of 1530 patients with primary breast cancer were included in the analysis, and the study cohort comprised 469 patients who underwent IBR and 1061 patients who underwent AFR with NSM/SSM.

\section{Treatments and Follow-Up}

NSM or SSM was performed by breast surgeons, whereas immediate breast reconstruction was performed by plastic surgeons using implants or autologous flaps. Most IBRs were performed using the direct-to-implant method. However, in patients requiring contralateral breast augmentation, the two-stage tissue expander/implant technique was adopted. AFR was performed using a pedicled/free transverse rectus abdominis musculocutaneous flap, free deep inferior epigastric artery perforator flap, extended latissimus dorsi flap, superficial inferior epigastric artery flap, or transverse upper gracilis flap.

Postoperatively, the patients were regularly followed up every three-six months for the first five years and annually thereafter. In patients suspected as having a locoregional recurrence, a fine-needle aspiration, core-needle, or excisional biopsy was performed for pathological confirmation. Lesions with a clear 
evidence of distant metastasis in the imaging evaluation were considered as recurrence without pathological examination.

\section{Propensity Score Matching}

To reduce the effects of selection bias and potential confounding factors on the comparisons of the oncologic outcomes between the IBR and AFR groups, a propensity score matching was performed to create balanced groups. The following baseline covariates for matching were included: age at diagnosis, T stage, N stage, molecular subtype, mastectomy type, adjuvant radiotherapy status, and follow-up period. The propensity scores were calculated for each of the 1530 patients using a multivariate logistic regression model, and the patients were matched 1:1 into the IBR and AFR groups using caliper restriction to the nearest neighbor without replacement. After the propensity score matching was performed, 469 patients each were included in the IBR and AFR groups.

\section{Statistical Analyses}

The endpoints of interest were locoregional recurrence-free survival (LRRFS), disease-free survival (DFS), distant metastasis-free survival (DMFS), and breast cancer-specific survival (BCSS). The locoregional recurrences were classified as biopsy-proven local recurrences in the ipsilateral skin/subcutaneous layer, chest wall, or nipple-areola complex and as regional recurrences (carcinoma metastases) in the ipsilateral axillary, supraclavicular, or internal mammary lymph nodes. Any other site of recurrence was considered as distant metastasis. Patients with initial distant metastasis were excluded from the locoregional recurrence group. In the case of concurrent locoregional recurrence and distant metastasis, each recurrence was counted as an event. The occurrence of contralateral breast cancer was considered as a new primary cancer and not as a recurrence. The follow-up period was calculated from the date of surgery for primary breast cancer. The last follow-up date was defined as the date of death or-if the patient survived through the follow-up period or was lost to follow-up-the date of the patient's last visit to our clinics for breast cancer surveillance. The LRRFS, DFS, DMFS, and BCSS rates were calculated using the Kaplan-Meier method and compared using the log-rank tests. The hazard ratios and $95 \%$ confidence intervals (Cls) were estimated using the Cox proportional hazards model. The chi-squared or Fisher's exact test was used for intergroup comparisons. All statistical analyses were performed using the International Business Machines Corporation (IBM) Statistical Package for the Social Sciences Statistics for Windows version 24.0 (IBM Corp., Armonk, NY, USA). Two-tailed $P$-values of < 0.05 were considered statistically significant.

\section{Results}

\section{Patient, Tumor, and Treatment Characteristics}

Table 1 shows the baseline characteristics according to the breast reconstruction methods used of the entire cohort before matching. Significant differences were observed regarding the age at diagnosis, $T$ stage, N stage, molecular subtype, mastectomy type, and radiotherapy status between patients who 
underwent IBR and AFR. The patients in the IBR group were more likely to be younger, at the earlier disease stage, and have more favorable molecular subtypes (i.e., hormone receptor [HR]+/human epidermal growth factor receptor-2 [HER2]- or HR+/HER2+) and to undergo NSM than those in the AFR group. Moreover, the patients in the AFR group were more likely to undergo adjuvant radiotherapy than those in the IBR group.

Table 1

Baseline characteristics of the study population before matching

\begin{tabular}{|c|c|c|c|c|c|c|}
\hline \multicolumn{2}{|l|}{ Variables } & IBR, $n=469$ & $\%$ & AFR, $n=1061$ & $\%$ & P-value \\
\hline \multicolumn{2}{|c|}{ Age, median (range), years } & \multicolumn{2}{|l|}{$43(20-70)$} & \multicolumn{3}{|l|}{$45(23-71)$} \\
\hline \multirow[t]{2}{*}{ Age, years } & $<50$ & 378 & 80.6 & 768 & 72.4 & 0.001 \\
\hline & $\geq 50$ & 91 & 19.4 & 293 & 27.6 & \\
\hline \multirow[t]{4}{*}{ T stage } & Tis & 85 & 18.1 & 122 & 11.5 & 0.003 \\
\hline & $\mathrm{T} 1$ & 249 & 53.1 & 583 & 54.9 & \\
\hline & $\mathrm{T} 2$ & 122 & 26.0 & 312 & 29.4 & \\
\hline & T3 & 13 & 2.8 & 44 & 4.1 & \\
\hline \multirow[t]{4}{*}{ N stage } & NO & 370 & 78.9 & 764 & 72.0 & 0.016 \\
\hline & N1 & 82 & 17.5 & 225 & 21.2 & \\
\hline & N2 & 13 & 2.8 & 48 & 4.5 & \\
\hline & N3 & 4 & 0.9 & 24 & 2.3 & \\
\hline \multirow[t]{4}{*}{ Molecular subtype } & $\mathrm{HR}+/ \mathrm{HER} 2-$ & 317 & 67.6 & 665 & 62.7 & 0.007 \\
\hline & HR+/HER2+ & 71 & 15.1 & 153 & 14.4 & \\
\hline & HR-/HER2+ & 57 & 12.2 & 203 & 19.1 & \\
\hline & TN & 24 & 5.1 & 40 & 3.8 & \\
\hline \multirow[t]{2}{*}{ Mastectomy type } & NSM & 332 & 70.8 & 525 & 49.5 & $<0.001$ \\
\hline & SSM & 137 & 29.2 & 536 & 50.5 & \\
\hline \multirow[t]{2}{*}{ Adjuvant RT } & Yes & 32 & 6.8 & 118 & 11.1 & 0.009 \\
\hline & No & 437 & 93.2 & 943 & 88.9 & \\
\hline $\begin{array}{l}\text { AFR, autologous fla } \\
\text { receptor; IBR, impla } \\
\text { skin-sparing maste }\end{array}$ & $\begin{array}{l}\text { construction; } \\
\text { ased reconstru } \\
\text { ly; TN, triple-n }\end{array}$ & $\begin{array}{l}\text { R2, human ep } \\
\text { ion; NSM, nip } \\
\text { ative }\end{array}$ & $\begin{array}{l}\text { rmal g } \\
\text { sparin }\end{array}$ & $\begin{array}{l}\text { wth factor rece } \\
\text { mastectomy; RT }\end{array}$ & $\begin{array}{l}\text { 2; HR, } \\
\text { diothei }\end{array}$ & $\begin{array}{l}\text { ormone } \\
\text { py; SSM, }\end{array}$ \\
\hline
\end{tabular}

After the propensity score matching was performed, 938 patients were 1:1 matched, comprising the wellbalanced IBR $(n=469)$ and AFR $(n=469)$ groups. Table 2 shows the clinicopathologic characteristics of 
the matched groups. No significant differences were observed between the matched groups in the selected matching and pathological variables (histotype, histologic grade, nuclear grade, lympho-vascular invasion [LVI] status, or Ki67 index). Table 3 shows the treatment characteristics of the matched groups. No significant differences were observed between the matched groups regarding the axillary surgery, adjuvant hormonal therapy, chemotherapy, and targeted therapy for HER2 + disease. 
Table 2

Clinicopathologic characteristics after propensity score matching

\begin{tabular}{|c|c|c|c|c|c|c|}
\hline Variables & & $\begin{array}{l}\text { IBR, } n= \\
469\end{array}$ & $\%$ & AFR, $n=469$ & $\%$ & P-value \\
\hline $\begin{array}{l}\text { Age, median (range), } \\
\text { years }\end{array}$ & & $43(20-70)$ & & $44(24-67)$ & & \\
\hline \multirow[t]{2}{*}{ Age, years } & $<50$ & 378 & 80.6 & 376 & 80.2 & 0.869 \\
\hline & $\geq 50$ & 91 & 19.4 & 93 & 19.8 & \\
\hline \multirow[t]{4}{*}{ T stage } & Tis & 85 & 18.1 & 68 & 14.5 & 0.472 \\
\hline & T1 & 249 & 53.1 & 267 & 56.9 & \\
\hline & $\mathrm{T} 2$ & 122 & 26.0 & 121 & 25.8 & \\
\hline & T3 & 13 & 2.8 & 13 & 2.8 & \\
\hline \multirow[t]{4}{*}{$\mathrm{N}$ stage } & NO & 370 & 78.9 & 371 & 79.1 & 0.828 \\
\hline & N1 & 82 & 17.5 & 85 & 18.1 & \\
\hline & N2 & 13 & 2.8 & 11 & 2.3 & \\
\hline & N3 & 4 & 0.9 & 2 & 0.4 & \\
\hline \multirow[t]{4}{*}{ Molecular subtype } & $\mathrm{HR}+/ \mathrm{HER} 2-$ & 317 & 67.6 & 318 & 67.8 & 0.931 \\
\hline & $\mathrm{HR}+/ \mathrm{HER} 2+$ & 71 & 15.1 & 71 & 15.1 & \\
\hline & HR-/HER2+ & 57 & 12.2 & 60 & 12.8 & \\
\hline & $\mathrm{TN}$ & 24 & 5.1 & 20 & 4.3 & \\
\hline \multirow[t]{5}{*}{ Histotype } & $\begin{array}{l}\text { In situ } \\
\text { cancer }\end{array}$ & 85 & 18.1 & 68 & 14.5 & 0.234 \\
\hline & IDC & 321 & 68.4 & 334 & 71.2 & \\
\hline & ILC & 22 & 4.7 & 23 & 4.9 & \\
\hline & Mixed & 21 & 4.5 & 14 & 3.0 & \\
\hline & Others & 20 & 4.3 & 30 & 6.4 & \\
\hline Ki67 index* & $<20 \%$ & 244 & 52.0 & 240 & 51.3 & 0.820 \\
\hline
\end{tabular}

AFR, autologous flap reconstruction; HER2, human epidermal growth factor receptor 2; HR, hormone receptor; IBR, implant-based reconstruction; IDC, invasive ductal carcinoma; ILC, invasive lobular carcinoma; LVI, lympho-vascular invasion; TN, triple-negative

*: Unknown, $\mathrm{n}=1$

$\star *$ : Unknown, $\mathrm{n}=155$ 


\begin{tabular}{|c|c|c|c|c|c|c|}
\hline Variables & & $\begin{array}{l}\text { IBR, } n= \\
469\end{array}$ & $\%$ & AFR, $n=469$ & $\%$ & P-value \\
\hline & $\geq 20 \%$ & 225 & 48.0 & 228 & 48.7 & \\
\hline \multirow[t]{2}{*}{ Histologic grade** } & 1,2 & 270 & 70.7 & 299 & 74.6 & 0.223 \\
\hline & 3 & 112 & 293.0 & 102 & 25.4 & \\
\hline \multirow[t]{2}{*}{ Nuclear grade } & 1,2 & 336 & 71.6 & 355 & 75.7 & 0.159 \\
\hline & 3 & 133 & 28.4 & 114 & 24.3 & \\
\hline \multirow[t]{2}{*}{ LVI } & Yes & 106 & 22.6 & 90 & 19.2 & 0.199 \\
\hline & No & 363 & 77.4 & 379 & 80.8 & \\
\hline \multicolumn{7}{|c|}{$\begin{array}{l}\text { AFR, autologous flap reconstruction; HER2, human epidermal growth factor receptor 2; HR, hormone } \\
\text { receptor; IBR, implant-based reconstruction; IDC, invasive ductal carcinoma; ILC, invasive lobular } \\
\text { carcinoma; LVI, lympho-vascular invasion; TN, triple-negative }\end{array}$} \\
\hline \multicolumn{7}{|l|}{ *: Unknown, n= 1} \\
\hline **: Unknown, $n=155$ & & & & & & \\
\hline
\end{tabular}


Table 3

Treatment characteristics in matched groups

\begin{tabular}{|c|c|c|c|c|c|c|}
\hline Variables & & IBR, $n=469$ & $\%$ & AFR, $n=469$ & $\%$ & P-value \\
\hline \multirow[t]{2}{*}{ Mastectomy type } & NSM & 332 & 70.8 & 331 & 70.6 & 0.943 \\
\hline & SSM & 137 & 29.2 & 138 & 29.4 & \\
\hline \multirow[t]{2}{*}{ Axillary surgery } & SLNB only & 411 & 87.6 & 412 & 87.8 & 0.921 \\
\hline & ALND & 58 & 12.4 & 57 & 12.2 & \\
\hline \multirow[t]{7}{*}{ Reconstruction methods } & DTI & 430 & 91.7 & NA & NA & NA \\
\hline & TEI & 39 & 8.3 & NA & NA & \\
\hline & TRAM & NA & NA & 282 & 60.1 & \\
\hline & DIEP & NA & NA & 162 & 34.5 & \\
\hline & eLD & NA & NA & 19 & 4.1 & \\
\hline & SIEA & NA & NA & 5 & 1.1 & \\
\hline & TUG & NA & NA & 1 & 0.2 & \\
\hline \multirow[t]{2}{*}{ Adjuvant RT } & Yes & 32 & 6.8 & 30 & 6.4 & 0.793 \\
\hline & No & 437 & 93.2 & 439 & 93.6 & \\
\hline \multirow[t]{2}{*}{ Adjuvant HT } & Yes & 308 & 65.7 & 329 & 70.1 & 0.142 \\
\hline & No & 161 & 34.3 & 140 & 29.9 & \\
\hline \multirow[t]{2}{*}{ Adjuvant CTx } & Yes & 155 & 33.0 & 163 & 34.8 & 0.581 \\
\hline & No & 314 & 67.0 & 306 & 65.2 & \\
\hline \multirow[t]{2}{*}{ Trastuzumab in HER2+ } & Yes & 52 & 40.6 & 51 & 38.9 & 0.781 \\
\hline & No & 76 & 59.4 & 80 & 61.1 & \\
\hline \multicolumn{7}{|c|}{$\begin{array}{l}\text { AFR, autologous flap reconstruction; ALND, axillary lymph node dissection; CTX, chemotherapy; DIEP, } \\
\text { deep inferior epigastric artery perforator flap; DTI, direct-to-implant; eLD, extended latissimus dorsi } \\
\text { flap; HER2, human epidermal growth factor receptor 2; HT, hormonal therapy; IBR, implant-based } \\
\text { reconstruction; NA, not applicable; NSM, nipple-sparing mastectomy; RT, radiotherapy; SIEA, } \\
\text { superficial inferior epigastric artery flap; SLNB, sentinel lymph node biopsy; SSM, skin-sparing } \\
\text { mastectomy; TEI, tissue expander/implant; TRAM, transverse rectus abdominis musculocutaneous } \\
\text { flap; TUG, transverse upper gracilis flap }\end{array}$} \\
\hline
\end{tabular}

\section{Recurrence and Survival}

After matching, the median follow-up periods were 68 months (range, 9-130) and 71 months (range, 36132) for the IBR and AFR groups, respectively. Table 4 shows the oncologic outcomes. No significant differences were observed between the IBR and AFR groups regarding the local recurrence $(7.2 \%$ vs. $5.1 \%$; 
$P=0.175)$, regional recurrence $(2.1 \%$ vs. $1.5 \% ; P=0.463)$, distant metastasis $(3.2 \%$ vs. $3.2 \% ; P=1.000)$, any first recurrence $(11.3 \%$ vs. $8.1 \% ; P=0.098)$, and breast cancer-associated death $(1.3 \%$ vs. $0.6 \% ; P=$ $0.315)$ rates. The 5 -year cumulative local recurrence rates of the IBR and AFR groups were $6.4 \%$ and $4.3 \%$, respectively. The median time to any first recurrence for the IBR and AFR groups were 34 months (range, 3-90) and 37 months (range, 7-94), respectively $(P=0.365)$.

Table 4

Oncologic outcomes

\begin{tabular}{|llllll|}
\hline Events & IBR, $\mathbf{n = 4 6 9}$ & $\%$ & AFR, $\mathbf{n = 4 6 9}$ & $\%$ & P-value \\
\hline Local recurrence & 34 & 7.2 & 24 & 5.1 & 0.175 \\
\hline Regional recurrence & 10 & 2.1 & 7 & 1.5 & 0.463 \\
\hline Distant metastasis & 15 & 3.2 & 15 & 3.2 & 1.000 \\
\hline Any first recurrence & 53 & 11.3 & 38 & 8.1 & 0.098 \\
\hline Breast cancer-associated death & 6 & 1.3 & 3 & 0.6 & 0.315 \\
\hline AFR, autologous flap reconstruction; IBR, implant-based reconstruction & & \\
\hline
\end{tabular}

Regarding the survival outcomes, no significant difference was observed between the IBR and AFR groups in the LRRFS (hazard ratio, 0.691; $95 \% \mathrm{Cl}, 0.433-1.102$; log-rank $P=0.118$ ), DFS (hazard ratio, 0.709; 95\% Cl, 0.468-1.076; log-rank $P=0.104$ ), DMFS (hazard ratio, 1.006; 95\% Cl, 0.491-2.059; log-rank $P=0.987$ ), or BCSS (hazard ratio, $0.445 ; 95 \% \mathrm{Cl}, 0.111-1.786$; log-rank $P=0.659)$ (Fig. 1a-d). The 5-year and 10 -year LRRFS rates were $91.4 \%$ and $88.9 \%$ in the IBR group and $93.7 \%$ and $91.4 \%$ in the AFR group, respectively. The 5-year and 10-year DFS rates were $89.5 \%$ and $86.7 \%$ in the IBR group and $92.2 \%$ and $89.3 \%$ in the AFR group, respectively. The 5-year and 10-year DMFS rates were $97 \%$ and $96.1 \%$ in the IBR group and $97.2 \%$ and $95.8 \%$ in the AFR group, respectively. The 5-year and 10 -year BCSS rates were $99.4 \%$ and $97.2 \%$ in the IBR group and $99.5 \%$ and $97.2 \%$ in the AFR group, respectively.

\section{Discussion}

A large proportion of patients with breast cancer who had mastectomy had undergone breast reconstruction with implants or autologous tissue $[18,19]$. The vast majority of previous outcome studies that compared the IBR and AFR techniques have focused on post-reconstructive complications, patient satisfaction, and/or the QoL of the patient [20-23]. This propensity score-matched study was specifically conducted to evaluate breast cancer outcomes and had found no significant differences regarding the local recurrence, distant metastasis, and survival rates between IBR and AFR in the setting of NSM/SSM.

Breast reconstruction methods using either implants or autologous tissue have their own pros and cons. Multiple previous studies investigating patient-reported outcomes have shown that patients who underwent AFR appear to have higher satisfaction and improved QoL as well as better psychosocial wellbeing than those who underwent IBR [20-23]. Furthermore, AFRs are less favorable than IBRs as they are 
associated with issues with donor site morbidity and a relatively higher incidence of overall complications, but IBRs were observed to have a higher reconstruction failure rate [24].

As an integral part of breast cancer management, the oncologic safety of breast reconstruction should be prioritized. However, to date, no randomized controlled data on the differences in the oncologic safety between mastectomy with breast reconstruction and without breast reconstruction or the oncologic outcomes of different reconstruction methods is available due to ethical concerns. Most existing studies based on retrospective data have documented that both IBR and AFR did not increase the risk of breast cancer recurrence [8-12]. However, conflicting results have indicated that postmastectomy AFR has an increased risk of cancer recurrence compared with mastectomy alone [25].

Few studies have focused on the comparison of the oncologic outcomes between the IBR and AFR groups, especially in the setting of NSM/SSM. Notably, substantial differences in the baseline characteristics and adjuvant treatment strategies between patients undergoing IBR and AFR are often observed, and a comparison of oncologic outcomes between these two approaches requires an appropriate matching of the potential confounding factors. In our prematching cohort, the patients in the IBR group were younger at diagnosis and more likely to undergo NSM compared with those in the AFR group. Moreover, the patients in the AFR group were more likely to present with an unfavorable disease status and receive adjuvant radiotherapy compared with those in the IBR group. To our knowledge, only one previous study has compared the breast cancer outcomes of IBR and AFR through a matched analysis. In a study by Ha et al., they compared the disease-free interval of 247 patients who underwent IBR and 249 patients who underwent AFR by matching the patients' age, tumor stage, and estrogen receptor status [13]. Although they found no significant difference in breast cancer recurrence between the matched groups, the AFR group showed a significantly higher distant metastasis rate associated with histologically aggressive tumors than the IBR group [13]. In that study, however, the number of patients with high Ki67 index included in the AFR group was significantly greater than that in the IBR group after matching, which may have a potential impact on the breast cancer prognosis [13]. In this study, 938 patients were 1:1 well-matched according to age at diagnosis, T stage, $\mathrm{N}$ stage, molecular subtype, mastectomy type, and adjuvant radiotherapy status. Moreover, the histopathological features, including tumor histotype, histologic grade, nuclear grade, LVI status, and Ki67 index status, as well as other treatment characteristics, such as axillary surgery, adjuvant hormonal therapy, chemotherapy, and targeted therapy for HER2 + disease, were also similar between the matched groups. However, no significant differences were observed in the recurrence rates and survival outcomes between the matched groups after a long-term follow-up.

Another emerging oncological concern regarding breast reconstruction is the potential effects of breast implants on cancer progression. Recently, cases of BIA-ALCL, which is a unique type of nonHodgkin T-cell lymphoma exclusively associated with textured implants, have been reported worldwide, with a substantial proportion of the cases occurring in patients with breast cancer after IBR [14]. The unexpected carcinogenicity of breast implants has raised additional concerns about any association between the breast implant and breast cancer recurrence. In a recent study by Lee et al., they compared the oncologic 
outcomes of patients with breast cancer according to the surface type of implants used for two-stage IBR [26]. Notably, they found that textured implants were statistically significantly associated with decreased DFS compared with smooth implants [26]. The findings of Lee et al. suggest that in addition to the risk of BIA-ALCL, textured implants may also be associated with the increased risk of breast cancer recurrence [26]. Conversely, other previous studies have investigated the recurrence risk following IBR without specifying the implant textures and found no increased risk of recurrence compared with mastectomy alone $[8,9]$.

This study is limited by its retrospective design from a single institution and the associated selection bias may exist even after matching the key clinical factors. Hidden confounding variables may include, but are not limited to, specific reconstruction methods, surgeon experience and characteristics, and other clinicopathologic factors. However, in the absence of randomized data, our propensity score-matched analysis of a robust series with long-term follow-up provides valuable data on the oncologic comparison of IBR and AFR and may help in the shared decision-making process between physicians and patients regarding breast reconstruction. Furthermore, although the incidence of BIA-ALCL is low, further research on safe alternative reconstruction approaches without BIA-ALCL risk is needed.

\section{Conclusions}

In this propensity score-matched analysis of breast cancer outcomes in a large series of patients with primary breast cancer who underwent NSM/SSM with immediate breast reconstruction, no significant differences were observed between the IBR and AFR groups.

\section{Declarations}

\section{Compliance with ethical standards}

Funding: None.

Conflict of interest: None.

Ethical approval: This study was approved by the institutional review board of Asan Medical Center, Seoul, Korea (No. 20201793). All procedures performed in studies involving human participants were in accordance with the ethical standards of the institutional and/or national research committee and with the 1964 Helsinki declaration and its later amendments or comparable ethical standards.

Informed consent: Because of the retrospective nature of the study, the requirement for informed consent was waived, and the study was conducted with the exemption of consent under IRB deliberation as it used a platform that offers unidentified clinical information for research purposes.

\section{References}


1. DeSantis CE, Ma J, Gaudet MM, Newman LA, Miller KD, Goding Sauer A et al (2019) Breast cancer statistics, 2019. CA Cancer J Clin 69:438-451

2. Kang SY, Kim YS, Kim Z, Kim HY, Kim HJ, Park S et al (2020) Breast cancer statistics in Korea in 2017: data from a breast cancer registry. J Breast Cancer 23:115-128

3. Rosenberg SM, Dominici LS, Gelber S, Poorvu PD, Ruddy KJ, Wong JS et al (2020) Association of breast cancer surgery with quality of life and psychosocial well-being in young breast cancer survivors. JAMA Surg 155:1035-1042

4. Eltahir Y, Werners L, Dreise MM, van Emmichoven IAZ, Jansen L, Werker PMN et al (2013) Quality-oflife outcomes between mastectomy alone and breast reconstruction: comparison of patient-reported BREAST-Q and other health-related quality-of-life measures. Plast Reconstr Surg 132:201e-209e

5. Ueda S, Tamaki Y, Yano K, Okishiro N, Yanagisawa T, Imasato M et al (2008) Cosmetic outcome and patient satisfaction after skin-sparing mastectomy for breast cancer with immediate reconstruction of the breast. Surgery 143:414-425

6. Galimberti V, Vicini E, Corso G, Morigi C, Fontana S, Sacchini V et al (2017) Nipple-sparing and skinsparing mastectomy: review of aims, oncological safety and contraindications. Breast 34(Suppl 1):S82-S84

7. Wong SM, Chun YS, Sagara Y, Golshan M, Erdmann-Sager J (2019) National patterns of breast reconstruction and nipple-sparing mastectomy for breast cancer, 2005-2015. Ann Surg Oncol 26:3194-3203

8. Eriksen C, Frisell J, Wickman M, Lidbrink E, Krawiec K, Sandelin K (2011) Immediate reconstruction with implants in women with invasive breast cancer does not affect oncological safety in a matched cohort study. Breast Cancer Res Treat 127:439-446

9. McCarthy CM, Pusic AL, Sclafani L, Buchanan C, Fey JV, Disa JJ et al (2008) Breast cancer recurrence following prosthetic, postmastectomy reconstruction: incidence, detection, and treatment. Plast Reconstr Surg 121:381-388

10. Lee SB, Lee JW, Kim HJ, Ko BS, Son BH, Eom JS et al (2018) Long-term outcomes of patients with breast cancer after nipple-sparing mastectomy/skin-sparing mastectomy followed by immediate transverse rectus abdominis musculocutaneous flap reconstruction: comparison with conventional mastectomy in a single center study. Medicine 97:e0680

11. Adam H, Docherty Skogh AC, Edsander Nord A, Schultz I, Gahm J, Hall P et al (2018) Risk of recurrence and death in patients with breast cancer after delayed deep inferior epigastric perforator flap reconstruction. Br J Surg 105:1435-1445

12. Geers J, Wildiers H, Van Calster K, Laenen A, Floris G, Vandevoort M et al (2018) Oncological safety of autologous breast reconstruction after mastectomy for invasive breast cancer. BMC Cancer 18:994

13. Ha JH, Hong KY, Lee HB, Moon HG, Han W, Noh DY et al (2020) Oncologic outcomes after immediate breast reconstruction following mastectomy: comparison of implant and flap using propensity score matching. BMC Cancer 20:78 
14. Leberfinger AN, Behar BJ, Williams NC, Rakszawski KL, Potochny JD, Mackay DR et al (2017) Breast implant-associated anaplastic large cell lymphoma: a systematic review. JAMA Surg 152:11611168

15. de Boer M, van Leeuwen FE, Hauptmann M, Overbeek LIH, de Boer JP, Hijmering NJ et al (2018) Breast implants and the risk of anaplastic large-cell lymphoma in the breast. JAMA Oncol 4:335-341

16. Nelson JA, Dabic S, Mehrara BJ, Cordeiro PG, Disa JJ, Pusic AL et al (2020) Breast implantassociated anaplastic large cell lymphoma incidence: determining an accurate risk. Ann Surg 272:403-409

17. DeCoster RC, Lynch EB, Bonaroti AR, Webster JM, Butterfield TA, Evers BM et al (2020) Breast implant-associated anaplastic large cell lymphoma: an evidence-based systematic review. Ann Surg 273:449-458

18. Jagsi R, Jiang J, Momoh AO, Alderman A, Giordano SH, Buchholz TA et al (2014) Trends and variation in use of breast reconstruction in patients with breast cancer undergoing mastectomy in the United States. J Clin Oncol 32:919-926

19. Song WJ, Kang SG, Kim EK, Song SY, Lee JS, Lee JH et al (2020) Current status of and trends in postmastectomy breast reconstruction in Korea. Arch Plast Surg 47:118-125

20. Santosa KB, Qi J, Kim HM, Hamill JB, Wilkins EG, Pusic AL (2018) Long-term patient-reported outcomes in postmastectomy breast reconstruction. JAMA Surg 153:891-899

21. Pusic AL, Matros E, Fine N, Buchel E, Gordillo GM, Hamill JB et al (2017) Patient-reported outcomes 1 year after immediate breast reconstruction: results of the Mastectomy Reconstruction Outcomes Consortium study. J Clin Oncol 35:2499-2506

22. Nelson JA, Allen RJ Jr, Polanco T, Shamsunder M, Patel AR, McCarthy CM et al (2019) Long-term patient-reported outcomes following postmastectomy breast reconstruction: an 8-year examination of 3268 patients. Ann Surg 270:473-483

23. Weichman KE, Broer PN, Thanik VD, Wilson SC, Tanna N, Levine JP et al (2015) Patient-reported satisfaction and quality of life following breast reconstruction in thin patients: a comparison between microsurgical and prosthetic implant recipients. Plast Reconstr Surg 136:213-220

24. Bennett KG, Qi J, Kim HM, Hamill JB, Pusic AL, Wilkins EG (2018) Comparison of 2-year complication rates among common techniques for postmastectomy breast reconstruction. JAMA Surg 153:901908

25. Isern AE, Manjer J, Malina J, Loman N, Mårtensson T, Bofin A et al (2011) Risk of recurrence following delayed large flap reconstruction after mastectomy for breast cancer. Br J Surg 98:659666

26. Lee KT, Kim S, Jeon BJ, Pyon JK, Mun GH, Ryu JM et al (2020) Association of the implant surface texture used in reconstruction with breast cancer recurrence. JAMA Surg 155:1132-1140

\section{Figures}


a

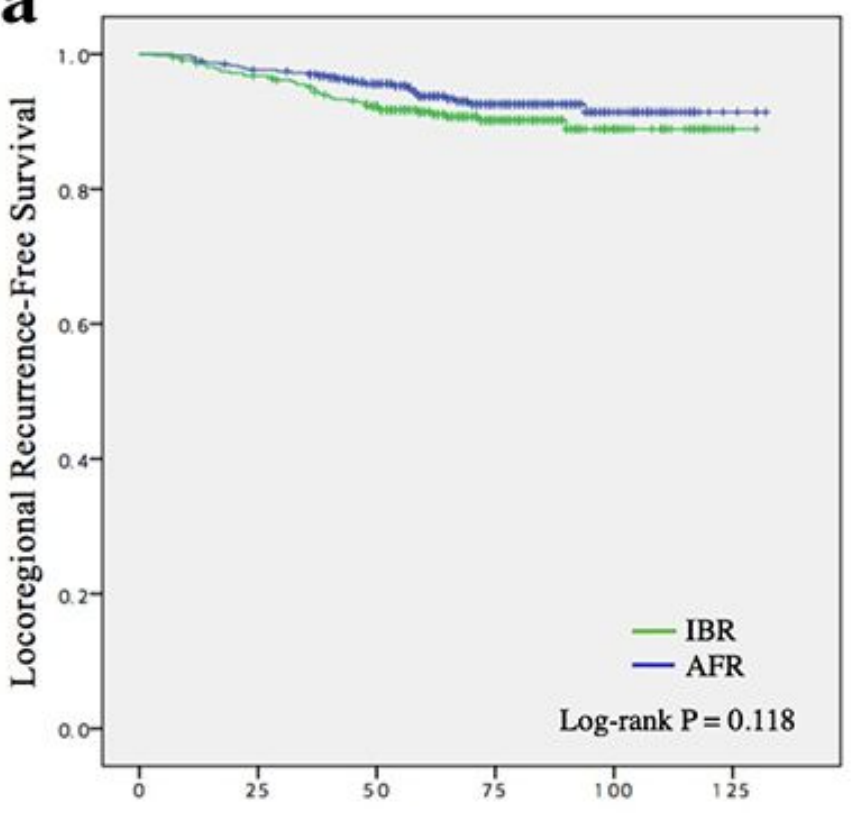

Time (months)
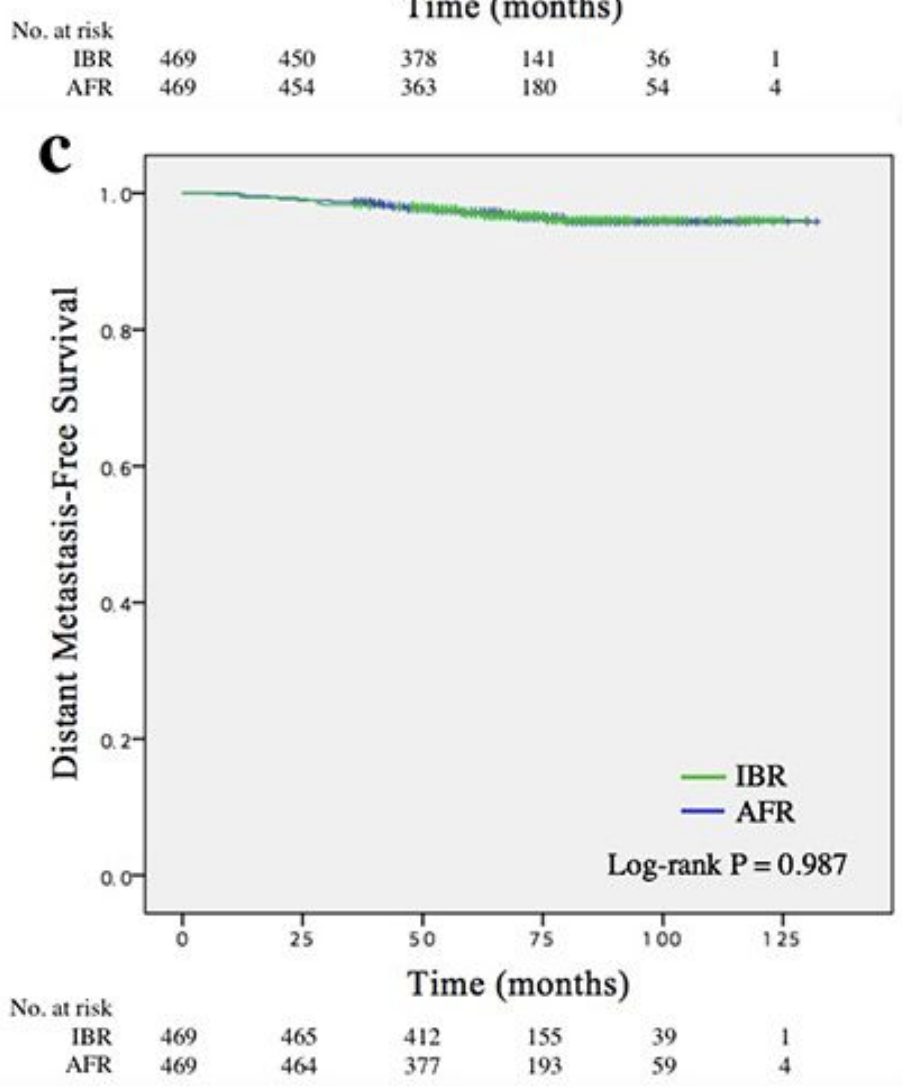

b
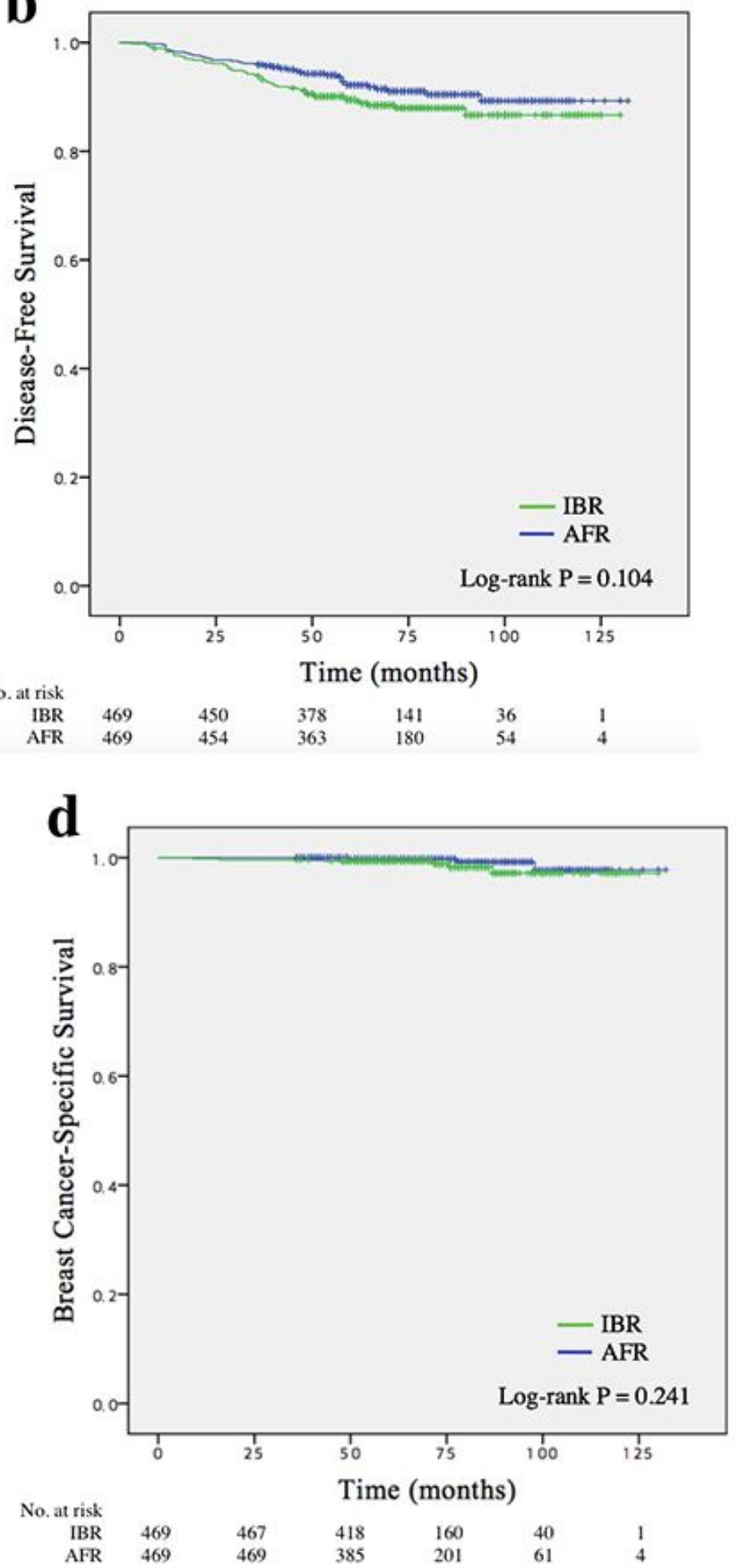

\section{Figure 1}

Propensity score-matched Kaplan-Meier survival analysis showing no significant differences in locoregional recurrence-free survival (a), disease-free survival (b), distant metastasis-free survival (c), and breast cancer-specific survival (d) between the immediate IBR and AFR groups. AFR, autologous flap reconstruction; IBR, implant-based breast reconstruction 